\title{
LOW POWER, LOW NOISE AMPLIFIERS DESIGN AND ANALYSIS FOR RF RECEIVER FRONT END USING 90NM CMOS TECHNOLOGY USED FOR WIMAX APPLICATIONS
}

\author{
M. Ramana Reddy ${ }^{1}$ Dr. N.S Murthy Sharma ${ }^{2}$ Dr. P. Chandra Sekhar ${ }^{3}$ \\ ${ }^{1}$ Department of Electronics and communication Engineering, \\ CBIT, Osmania University, Hyderabad, TS, INDIA \\ ${ }^{2}$ Department of Electronics and communication Engineering, SIT , JNTU, Hyderabad, \\ ${ }^{3}$ Department of Electronics and communication Engineering, , Osmania University,
}

\begin{abstract}
This work is mainly to ensure the reliability of low power low noise amplifier design and analysis which is useful for $4 G$ receiver front ends in particularly WIMAX applications. The low noise amplifiers implemented by using different topologies namely (a) Cascoded Common source amplifier technique(b) Folded Cascode amplifier technique (c) Shunt feedback amplifier technique (d) Current reuse Common gate amplifier with gm boosted technique with $90 \mathrm{~nm}$ TSMC CMOS technology, which is used for WIMAX applications with $1 \mathrm{~V}$ supply. In order to simulate and measurement the parameters such as Scattering parameters(S21, S12 S11. S22 ), noise-figure, input matching, output matching ,stability, linearity the Cadence, Agilent technologies ADS and lab view graphical software have been used and Compare the performance of the various parameters .
\end{abstract}

\section{KEYWORDS}

RF CMOSLNA, WIMAX, soc, noise figure

\section{INTRODUCTION}

The communication system that comprises of transmitter and receiver will experience not only attenuation but also the interference at the receiver end. The signal strength will be normally in milli-volt range hence unable to drive the demodulator circuitry; therefore it is mandatory to amplify the signal before giving it to the demodulator circuit. But the amplifier will not only amplify the signal but also amplify the noise as well. Hence amplifier with minimum noise addition is required. So LNA is essential and first active block in receiver front end[1]

The emerging wireless consumer market has experienced a remarkable improvement since the introduction of the first modern mobile phone systems, new application areas, high data rates and increase in the number of subscribers, a prime goal of the IC manufactures is to provide low cost solutions. The wireless communication area network standards, such as WIMAX, Bluetooth, WiFi technologies of all the components make it possible to integrate on a single silicon chip 
International Journal of VLSI design \& Communication Systems (VLSICS) Vol.7, No.1, February 2016

including transceiver sections .So the SOC (system on chip )solution to enable with CMOS technology [2].

WIMAX is a trade mark for a family of wireless communication protocols that provide fixed and mobile internet access . This is a wireless communication system also known as IEEE 802.16 family standard.WIMAX is a internet protocol based similar to 802.11/Wi-Fi networks with the coverage and quality service of cellular networks WIMAX can provide broad band wireless access up to 30 miles for fixed stations and 3-10 miles for mobile stations .Data rates up to $40 \mathrm{MB} / \mathrm{s}$ for mobile stations and, $1 \mathrm{gb} / \mathrm{s}$ for fixed stations.[3].

This paper summarises as follows ,Section 2 describes the topologies of the implemented low power low noise amplifier. Section 3 represents the proposed circuit design. The analysis of simulation measured results presented in section 4 the conclusions in section 5 followed references in Section 6.

\section{LOW NOISE AMPLIFIERS}

LNA (low noise amplifier) is a crucial element which is used in front end circuit of receiver because of its gain and noise characteristics are closely related to the system sensitivity and dynamic range. Receiving multiple signals at different power levels over different frequency ranges .It gives low noise and high linearity. The maximum power gain $50 \mathrm{ohm}$ termination for proper operation and can route the LNA to the antenna which is located an unknown distance away without worrying about the length of the transmission line.

\subsection{Cascoded CS (common source) amplifier topology}

This is widely used architecture as shown in fig .1 cacode technique with inductive degenerated topology was improved the isolation between input and output matching along with enhancement of gain of the amplifier as shown in fig, the cascade transistor $\mathrm{Q}_{2}$ reduces the voltage gain of $\mathrm{Q}_{1}$. So that it improves the reverse isolation [6] and also $\mathrm{Q}_{2}$ transfers the current $\mathrm{I}_{\mathrm{d}}$, to $\mathrm{R}_{\mathrm{L}}$ by providing the gain equal to the basic common source, by reducing the parasitic capacitances, it improves the performance of the amplifier at higher frequencies with reducing Miller effect.

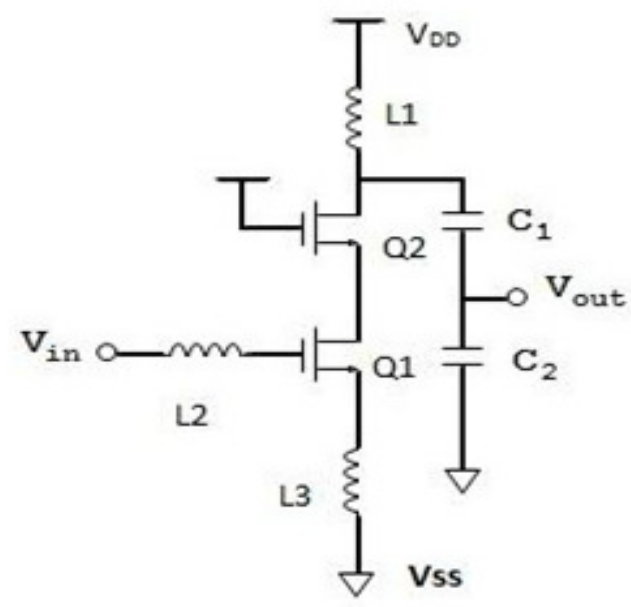

Figure 1 : Cascoded CS (common source)amplifier topology 


\subsection{Folded cascode amplifier topology}

Folded cascode topology is used for very low voltage application as shown in fig 2. It has low operated supply voltages as the PMOS and NMOS transistors are placed in parallel between the ground rail and supply. The PMOS cascode transistorQ $\mathrm{Q}_{2}$ reduces the input capacitance and offers good reverse isolation with better stability [7]. Improved trans-conductance, gain and slew rate by reducing the bias current of ideal deice.

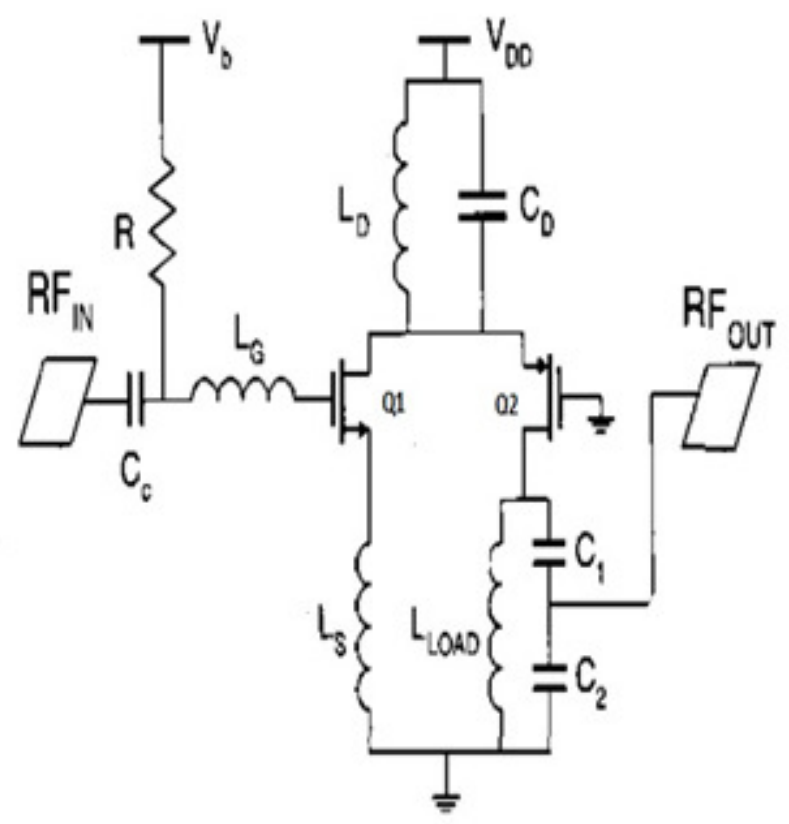

Figure2: Folded cascode amplifier topology

\subsection{Shunt feedback low noise amplifier topology}

The resistive shunt feedback provides wideband input and output matching with low noise figure(NF) degradation by reducing the $\mathrm{Q}$ factor of the narrow band LNA input and flatters the pass band gain as shown in fig(3), it is able to attain a very high linearity [8] improves the gain, which is set by feedback. The feedback components are combination of a resistor in series with a capacitor which increases the bandwidth and gain with linearization. The high input impedance and high frequency performance improved to MOSFETS by providing an additional inductor can be placed in series with the capacitor and resistor [8].The band pass filter connected at input includes the input impedance of a cascode amplifier improves the better performance with low power dissipation but due to this band pass filter the chip area is high and noise figure degradation.

\subsection{Current reuse Common gate amplifier topology}

As shown in fig (4) ,the current reuse common gate LNA has better reverse isolation compare with common source LNA. The purpose of a CG input stage improves stability over the design of common source LNA. It attains noise and gain performance comparably low power and less chip area by the current reverse technique with boosting gm. The dual inductive degeneration and resistive current reuse techniques are superimposed in the first stage for broad band, noise and 
International Journal of VLSI design \& Communication Systems (VLSICS) Vol.7, No.1, February 2016 input impedance matching[6].To improve bandwidth the inductive degenerated technique is implemented in the second stage .By combining a NMOS and PMOS transistor between the supply rails as shown in fig 4 .

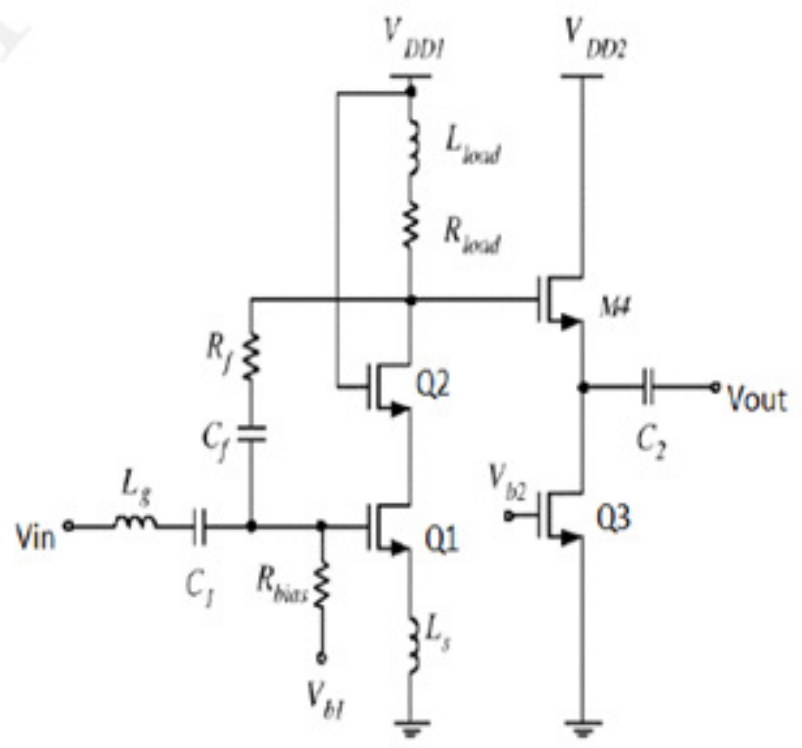

Figure 3 : Shunt feedback low noise amplifier topology

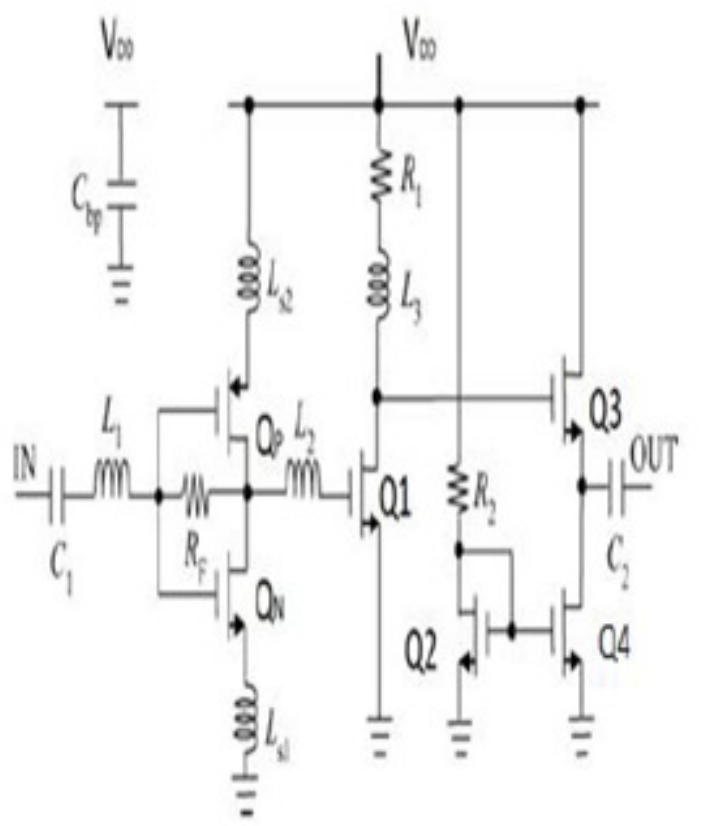

Figure :4 Current reuse Common gate amplifier topology

\section{Proposed Circuit DesignS}

The WIMAX receiver performance specifications requirements are shown in table 1.According to IEEE 802.16 family standard the specifications of various parameters. 
International Journal of VLSI design \& Communication Systems (VLSICS) Vol.7, No.1, February 2016

TABLE I: WIMAX RECEIVER REQUIREMENTS

\begin{tabular}{|l|l|l|}
\hline S.No & PARAMETER & SPECIFICATIONS OF WIMAX \\
\hline 1 & Radio technology & MIMO-SOFDMA \\
\hline 2 & Range & 30 miles \\
\hline 3 & Speed & $70 \mathrm{Mbps}$ \\
\hline 4 & Frequency range & $2-10 \mathrm{Ghz}$ \\
\hline 5 & $\begin{array}{l}\text { Receiver maximum input level } \\
\text { on channel rejection tolerance }\end{array}$ & $\geq 30 \mathrm{dBm}$ \\
\hline 6 & Channel bandwidth & $2-20 \mathrm{Mhz}$ \\
\hline 7 & Noise figure & $\leq 7 \mathrm{~dB}$ \\
\hline 8 & First adjacent channel rejection & $\geq 4 \mathrm{~dB}$ \\
\hline 9 & $\begin{array}{l}\text { Second adjacent channel } \\
\text { rejection }\end{array}$ & $\geq 23 \mathrm{dBm}$ \\
\hline
\end{tabular}

The receiver front end specifications requirements are shown in table 2

\begin{tabular}{|l|l|l|}
\hline S.No & Parameter & Low noise amplifier \\
\hline 1 & Gain & $20 \mathrm{~dB}$ \\
\hline 2 & Noise figure & $3 \mathrm{~dB}$ \\
\hline 3 & Linearity & $-10 \mathrm{~dB}$ \\
\hline 4 & Input and Output matching & $\leq-10 \mathrm{~dB}$ \\
\hline
\end{tabular}

\subsection{Cascoded common source Low noise amplifier:}

The input impedance $z_{\text {in }}$ equal to

Zin $=(\mathrm{gm} / \mathrm{Cgs}) . \mathrm{L} 3+1 /(\mathrm{s} . \mathrm{Cgs})+\mathrm{s} .(\mathrm{L} 2+\mathrm{L} 3)$

$\omega 0=1 / \sqrt{ }(L 2+L 3 . C g s)$

Zin $=(\mathrm{gm} / \mathrm{Cgs}) . \mathrm{L3}$ (At Resonance)

Where $\mathrm{g}_{\mathrm{m}}$ is trans conductance, $\mathrm{C}_{\mathrm{gs}}$ gate to source capacitance, Ls source inductance, $\mathrm{L}_{\mathrm{G}}$ gate inductance respectively.

The input impedance reduces as shown in equation computed with the value of $\mathrm{L}_{3}$ at a resonant frequency shown in fig 5.The degenerating inductor $\mathrm{L}_{3}$ gives the real input impedance of LNA is computed with the value of $\mathrm{L}_{3}$ determine the value of gate inductance $\mathrm{L}_{2}$, that will set the resonant frequency is calculated .In order to reduce the junction capacitance in the layout, the width of the cascode transistor $\mathrm{Q}_{2}$ set equal to the width of the input transistor. The output matching network was composed of the drain inductor L1 and the output capacitors $\mathrm{C} 1$ and $\mathrm{C} 2$ will designed. 


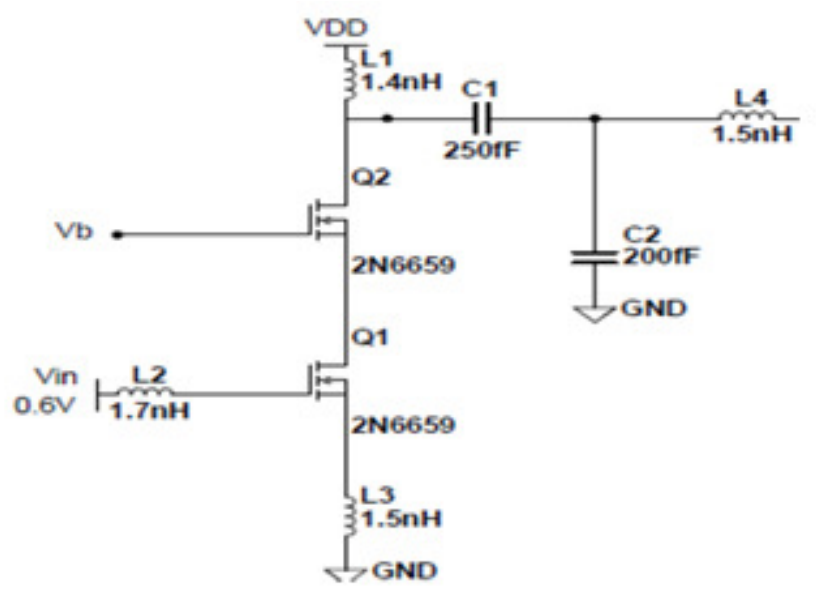

Figure 5 : Cascoded CS (common source) amplifier topology

\subsection{Folded cascode amplifier}

The input impedance of the folded amplifier is described by the source inductance Ls while gate inductance LG is computed based on the resonant frequency. The inductor LD resonates with drain junction capacitance of $\mathrm{Q}_{1}$ and the source capacitance of $\mathrm{Q}_{2}$. The output matching network made by the inductor Lload and capacitor $\mathrm{C}_{1}$ and $\mathrm{C}_{2}$. The schematic shown in fig 6 . below.

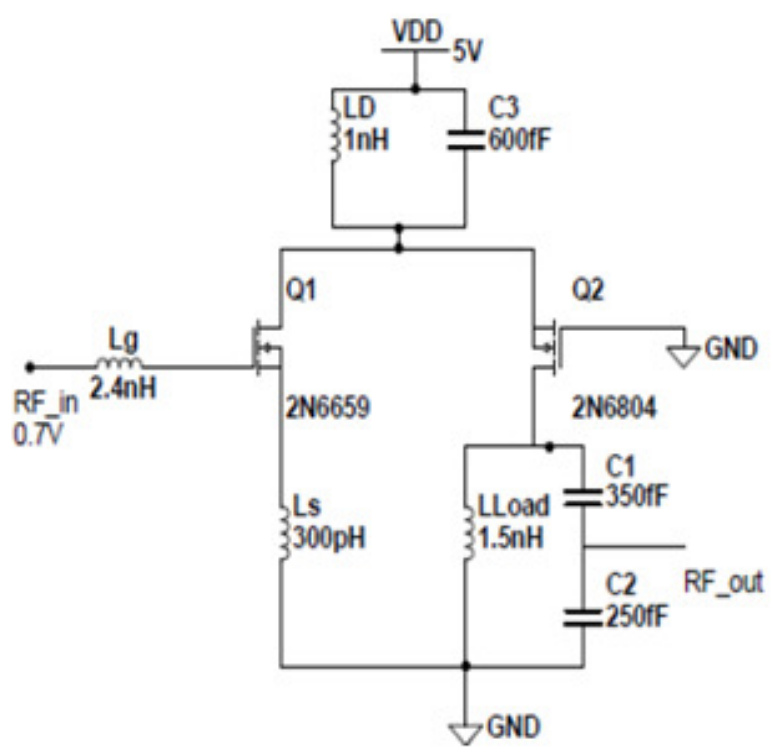

Figure 6 : Folded cascode amplifier topology

\subsection{Shunt feedback amplifier topology}

The schematic of shunt feedback amplifier shown in fig 6 . Power gain can be adjusted by the value of feedback resistor as shown in below equation. Where $R_{F}$ is feedback resistor , $Z_{O}$ output impedance and the transducer gain. Inductor Ls is added for simultaneously noise and input ,output matching and $\mathrm{L}_{\mathrm{G}}$ is placed at the gate of the transistor $\mathrm{Q}_{4}$ to aid in matching. The capacitances CF.C1 and $\mathrm{C} 2$ is used for ac coupling purpose .The feedback capacitor for biasing purpose. 


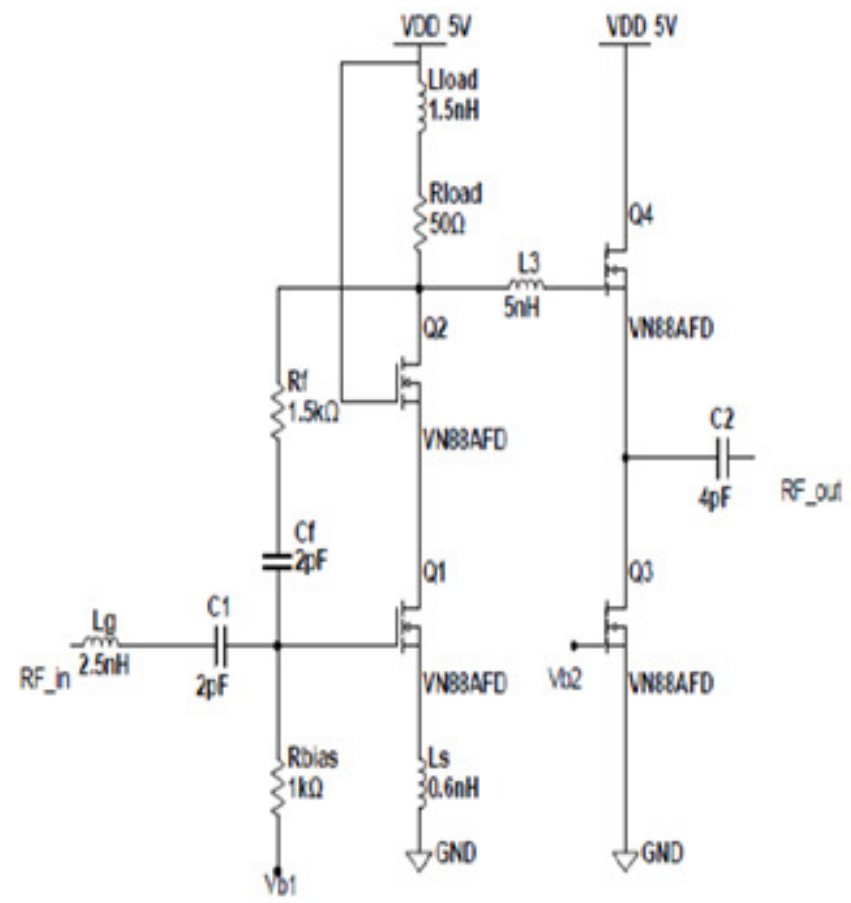

Figure 7 : Shunt feedback low noise amplifier topology

\subsection{Current reuse common gate low noise amplifier}

The schematic for current reuse common gate LNA shown in fig below 8. The resistive current reuse amplifier utilizes dc current reuse to save the power consumption and to improve transconductance $g_{m}$ to the amplifier. This composed two stages, the first stage of amplifier increases the voltage gain with low power dc supply voltage, it adopts a current reuse topology with self biasing by a feedback resistor Rf as shown in fig.

The disadvantage of this topology is parasitic capacitances due to this degradation of input impedance and the $-3 \mathrm{~dB}$ bandwidth at high frequency, to overcome this dual source degenerated inductors $\left(\mathrm{L}_{\mathrm{S} 1}\right.$ and $\mathrm{L}_{\mathrm{s} 2}$ )and inter stage inductor $\mathrm{L}_{2}$ are proposed for the tuning of the parasitic capacitances .LC network ( $\mathrm{L} 1$ and $\mathrm{C} 1$ ) combined with dual degenerated inductors $\left(\mathrm{L}_{\mathrm{S} 1}\right.$ and $\left.\mathrm{L}_{\mathrm{S} 2}\right)$ for input matching and intrinsic capacitances of current reuse topology to form a multi section LC ladder network to achieve a wideband matching with $50 \mathrm{ohm}$ characteristic impedance.

The total trans-conductance in this stage is $\mathrm{g}_{\mathrm{mt}}$ is

$\mathrm{gmT}=\mathrm{gmn} /(1+j \omega L s 1 . g m n)+\mathrm{gmp} /(1+\mathrm{j} \omega \mathrm{Ls} 2 . \mathrm{gmp})$

The voltage gainAV1 of the first stage LNA

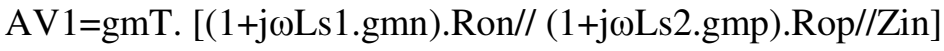

The input impedance Zin of LNA

$\mathrm{Zin}=\mathrm{j} \omega \mathrm{L} 1+\mathrm{Zsd} / / \mathrm{Zfb}$ 


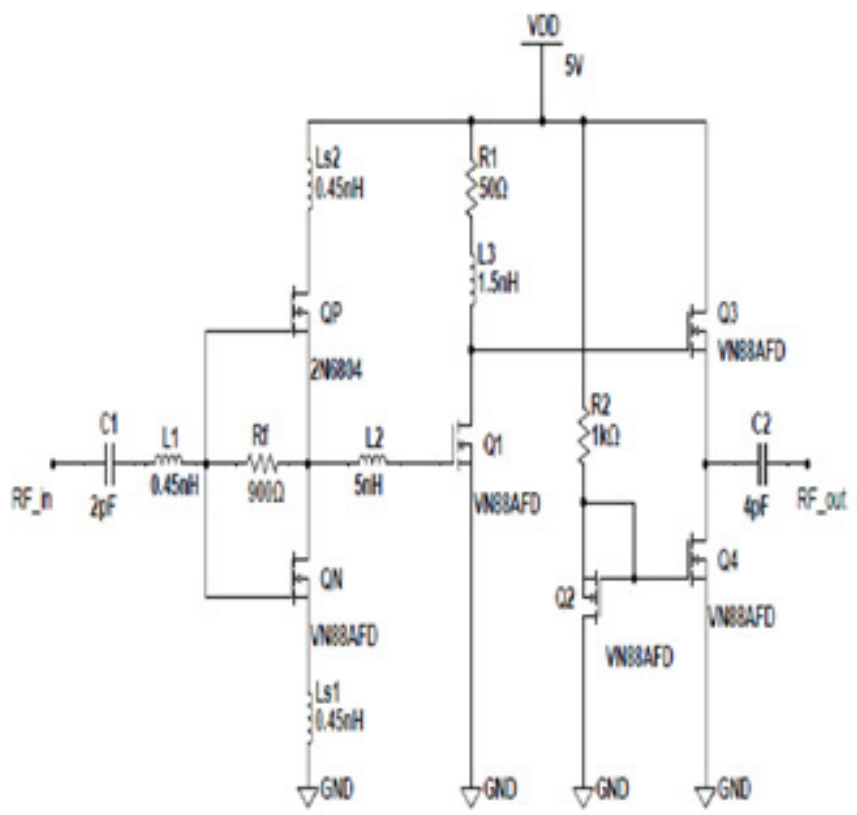

Figure 8 : Current reuse Common gate amplifier topology

\section{RESULTS}

The LNA topologies designed by using the $90 \mathrm{~nm}$ CMOS process .The LNAS were designed to operate at the unlicensed national information infrastructure (U-NII) band of $5.75 \mathrm{GHz}$ to 5.85 $\mathrm{GHz}$.The measurement taken at $5.8 \mathrm{GHz}$. The shunt feedback amplifier achieved the highest gain with $20 \mathrm{~dB}$ followed by the cascaded common source amplifier with $14 \mathrm{~dB}$ and the folded cascode achieved the lowest gain with a gain of $13 \mathrm{~dB}$

The linear zing effect of feedback gives the shunt feedback amplifier its wideband characteristics to the narrow band characteristic of these cascode amplifier. The total double side band noise figure as shown in fig 9.The noise figure of the LNA topologies are $1.7 \mathrm{db}$ for cascoded common source $1.7 \mathrm{~dB}$ for the folded cascode and $2.63 \mathrm{~dB}$ for the shunt feedback amplifier . The stability factor plot shown in fig 10 . All topologies are un conditionally stable with stability factor larger than 1 at the required frequency.

The simulation S Parameter results for all topologies ,table 3:

\begin{tabular}{|l|l|l|l|l|l|l|}
\hline S.No & Topology & $\begin{array}{l}\text { Frequency } \\
(\mathrm{GHz})\end{array}$ & $\begin{array}{l}\text { Pdc } \\
(\mathrm{mw})\end{array}$ & $\begin{array}{l}\text { Gain } \\
(\mathrm{dB})\end{array}$ & $\begin{array}{l}\text { IIP3 } \\
(\mathrm{dB})\end{array}$ & $\begin{array}{l}\text { Noise figure } \\
(\mathrm{dB})\end{array}$ \\
\hline 1 & Cascaded CS & 5.8 & 20 & 14 & -7.42 & 1.7 \\
\hline 2 & Folded cascode & 5.8 & 47.5 & 13 & -6.2 & 1.8 \\
\hline 3 & Shunt feedback & 5.8 & 55.5 & 20 & -5.15 & 2.7 \\
\hline 4 & Current reuse CG & 5.8 & 16.1 & 18 & -7.35 & 1.8 \\
\hline
\end{tabular}


International Journal of VLSI design \& Communication Systems (VLSICS) Vol.7, No.1, February 2016

\begin{tabular}{|l|l|l|l|l|l|}
\hline S.No & Topology & $\begin{array}{l}\mathrm{S}_{21} \\
20\end{array}$ & $\begin{array}{l}\mathrm{S}_{12} \\
-10\end{array}$ & $\begin{array}{l}\mathrm{S}_{11} \\
-10\end{array}$ & $\begin{array}{l}\mathrm{S}_{22} \\
-20\end{array}$ \\
\hline 1 & Cascaded CS & 14 & -9.55 & -14.5 & -23.8 \\
\hline 2 & Folded cascode & 13 & -12.4 & -9 & -26.03 \\
\hline 3 & Shunt feedback & 20 & -11.4 & -24 & -31.24 \\
\hline 4 & Current reuse CG & 18 & -9.7 & -10.3 & -46 \\
\hline
\end{tabular}

According to above table reuse isolation better than $-20 \mathrm{~dB}$. The current reuse common gate LNA can achieved $-46 \mathrm{~dB}$.The third order interception point represents the linearity of the low noise amplifier.

-

\section{Current reuse Common gate LNA}

-

-

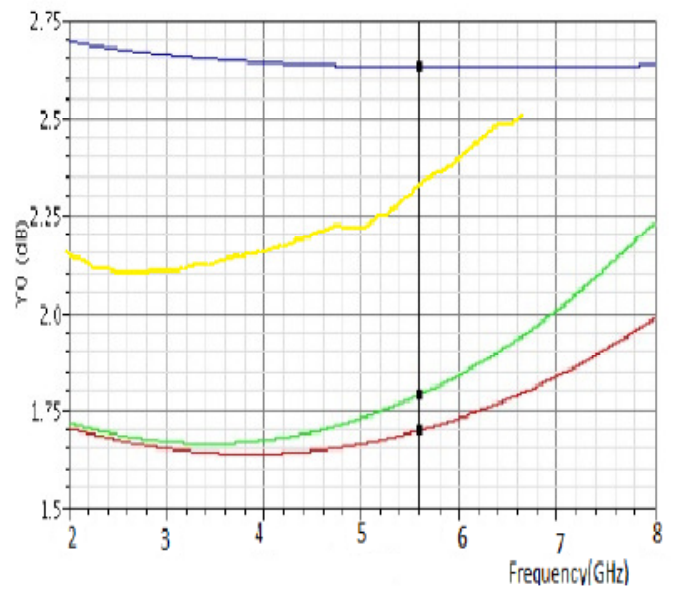

Figure: 9 frequency versus gain

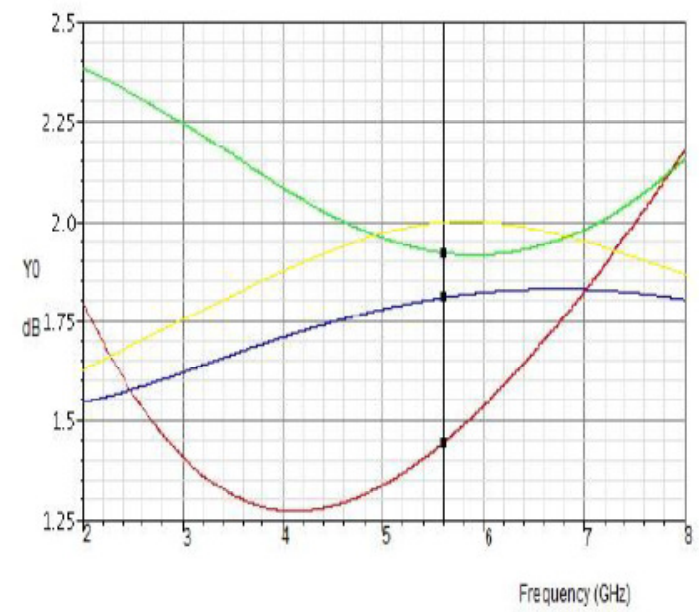

Figure: 10 Frequency versus gain 


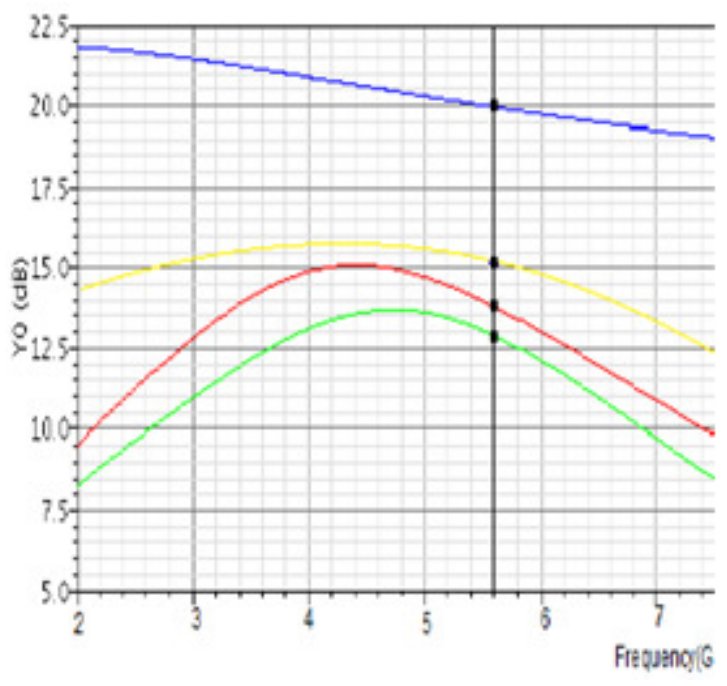

Figure: 11 Frequency versus admittance

\subsection{Comparison of various parameters :}

From the above comparison table cascoded common source low noise amplifier achieved the best figure of merit .Due to high gain of the shunt feedback amplifier. So the best to use in the front end of receivers is shunt feedback amplifiers.

\section{CONCLUSION}

A standard CMOS 90nm technology with 1V supply was used for all the topologies of cascoded common source amplifier ,the folded cascoded amplifier, shunt feedback amplifier and current reuse common gate low noise amplifier according to requirements of receiver front end .So that choose the best low noise amplifier depends upon performance of parameters particular low noise amplifier. From this presented work the cascoded common source topology attains lowest noise figure due to better input matching using inductive degeneration .The folded cascode technology is also attained low noise figure .The cascoded common source topology is also attains the lowest power dissipation because of it contains only one current branch. The shunt feedback amplifier attained the highest gain by changing the value of the feedback resistor. The current reuse CG LNA topology is proposed in narrow band LNA designs can successfully extended to UWB purpose because of good linear performance accept the high noise figure comparatively other LNAs.

\section{REFERENCES}

[1] Wikipedia Contributors. (2009,April). In Wikipedia, the free encyclopedia. Retrieved July 2009,from http://en.wikipedia.org/wiki/WiMAX.

[2] Kalantari, Fatemeh, Masoumi et al., A Low Power $90 \mathrm{~nm}$ LNA with an Optimized Spiral Inductor Model for WiMax Front End. Circuits and Systems, 2006.MWSCAS '06.49th IEEE International Midwest Sympos. 
International Journal of VLSI design \& Communication Systems (VLSICS) Vol.7, No.1, February 2016

[3] Low-power $5 \mathrm{GHz}$ LNA and VCO in $90 \mathrm{~nm}$ RF CMOS Interuniv. Microelectron. Center, Leuven, Belgium Aspemyr, L. ; Jeamsaksiri, W. ; Ramos, J. ; Mercha, A. ; Jenei, S. ; Thijs, S. ; Garcia, R; Jacobsson, H. ;Wambacq, P. ; Donnay, S. ; Decoutere, S.

[4] IEEE standard 802.16. "Air interface for Fixed BroadbandWireless Access Systems", part 16, Oct. 1, 2004.

[5] Lee, T., "The Design of CMOS Radio-Frequency Integrated Circuits," Cambridge: Cambridge University Press, 1998.Atallah, J. G., Rodriguez, S., Zheng, L.-R., Ismail, M.

[6] A Direct Conversion WiMAX RF Receiver Front-End in CMOS Technology. Signals, Circuits and systems 2007. ISSCS 2007. International Symposium on.Volume 1, 13-14J Page(s): 1 - 4.

[7] IEEE standard 802.16. “Air interface for Fixed Broadband Wireless Access Systems", part 16, Oct. 1, 2004

[8] Lee J H, Chen C C, Lin Y S. 0.18 _m 3.1-10.6 GHz CMOS UWB LNA with 11.4 _ 0.4 dB gain and 100.7 _17.4 ps group-delay. Electron Lett, 2007, 43(24): 1359.

[9] Wang R L, Lin M C, Lin C C, et al. A 1 V full-band cascoded UWB LNA with resistive feedback. IEEE International Workshop on Radio-Frequency Integration Technology, 2007: 188.

[10] Lu Y, Yeo K S, Cabuk A, et al. A novel CMOS lownoise amplifier design for 3.1-to-10.6-GHzultrawide- band wireless receivers. IEEE Trans CircuitsSyst I: Regular Papers, 2006, (8):1683

[11] Ismail A, Abidi A A. A 3-10-GHz low-noise amplifier with wideband LC-ladder matching network. IEEE J Solid-State Circuits, 2004, 39(12): 2269.

[12] Razavi, B. (2001). Design of Analog CMOS Integrated Circuits. Boston: McGraw Hill.

[13] Johns, D.Ken Martin, K., “Analog Integrated Circuit Design,” Wiley, 1996.

[14] R. Brederlow et al., "A mixed signal design read map", IEEE Design \& Test of Computers, Vol.18,No.6, nov.-Dec. 2001 pp.34-36. 3544 International Journal of Engineering Research \& Technology (IJERT Vol. 2, Issue 10, October - 2013ISSN: 2278-0181. 